\title{
Study of the Two Steps and One-Pot Two-Step Mechanochemical Synthesis of Annulated 1,2,4-Triazoles
}

\author{
Lori Gonnet,* Christiane André-Barrès, Brigitte Guidetti, Alain Chamayou, Christophe Menendez, \\ Michel Baron, Rachel Calvet, and Michel Baltas*
}

\begin{abstract}
The mechanochemical synthesis of 1,2,4-triazoles by using a planetary ball-mill is studied starting from hydralazine hydrochloride. Excellent conditions were found for achieving total conversion to intermediate hydrazones in a few minutes in the presence of pyrogenic S13 silica as grinding auxiliary. The conversion to annulated 1,2,4-triazoles was optimal with iodobenzene diacetate (IBD) when using nonphenolic hydrazones, while $\mathrm{SeO}_{2}$ was found to be efficient for phenolic compounds. The one-pot two-step synthesis was also successfully conducted for the first time leading to annulated 1,2,4-triazoles. Finally, green metrics showed the efficiency of the method in comparison to the conventional syntheses of hydrazone 10 and triazole 13.
\end{abstract}

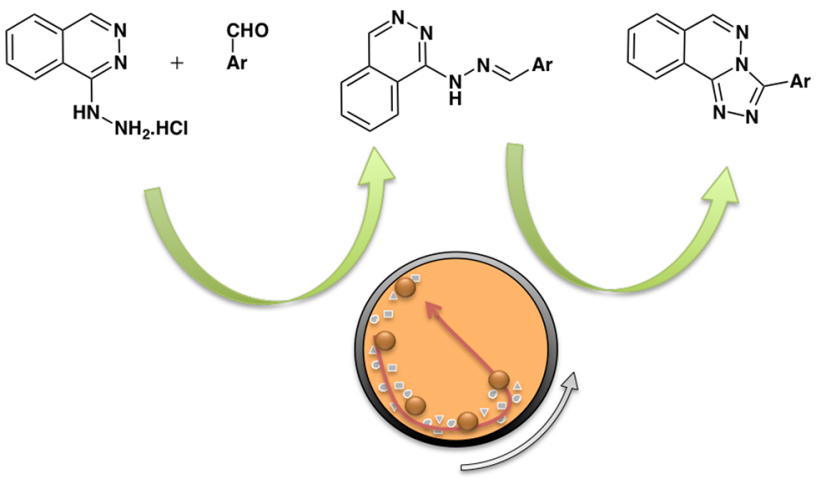

KEYWORDS: Hydrazones, Annulated triazoles, Mechanochemistry, Ball-milling, Pyrogenic silica, Green metrics

\section{INTRODUCTION}

Creativity in organic synthesis has rendered possible the synthesis of incredible large, different, and complex families of molecules. Nevertheless, upon the end of the last century, chemists were conscious that organic synthesis generally suffers from the large amounts of toxic waste that are produced during syntheses. ${ }^{1}$ In that respect, green chemistry and sustainability are becoming increasingly important. ${ }^{2,3}$ The green chemistry field has defined metrics to evaluate the environmental impact of chemical processes where solvents are identified as the major contributors of undesirable waste. ${ }^{4,5}$ The reduction of solvent waste became a major motivation for the development of solvent-free synthetic reaction protocols. ${ }^{6-9}$ In addition, insolubility problems in organic solvents can be overcome under these conditions. While solvent-free reactions can be carried out with classical laboratory equipment or by using microwave heating, the application of organic synthesis mechanochemistry is a continuously improving field of research. Ball milling was found to be an excellent method for many named organic reactions. ${ }^{7-14}$ The mechanochemical reaction environment can be modified further by the addition of a small amount of liquid. The so-called liquid-assisted grinding (LAG) has become an important technique in the expanding mechanochemistry field. ${ }^{15,16}$ One of several challenges in the organic synthesis mechanochemistry field is the attainment of the ability to run one-pot two-step or more syntheses in various multistep synthetic processes. One-pot procedures usually require solvent compatibility and have to address the possibility of side product formation. ${ }^{17}$ The onepot procedures in the mechanochemistry field have the advantage of overcoming these problems and especially the use of solvents compatible with several consecutive steps. In that respect, mechanochemistry amplifies sustainability metrics by running back-to-back solventless reactions. Multistep mechanochemical procedures have been successfully applied to the syntheses of O-glycosides, ${ }^{18}$ bioactive hydantoins, ${ }^{19}$ extended iptycenes, ${ }^{20}$ amides $^{21}$ and organometallics, ${ }^{22}$ and metalation/transmetalation procedures ${ }^{23}$ where problems can occur with the use of solution based synthesis due to limited solubility.

The 1,2,4-triazole-based, biologically active compounds have found enormous applications in medicinal and agricultural sciences. A great number of drugs are extensively used in clinics. Among them, we can point to the antifungal fluconazole $\mathbf{1}$, antitumoral letrozole $\mathbf{2}$, and the antiviral ribavirin 3, (Figure 1) ${ }^{24}$ while several triazole based compounds like epoxiconazole 4 play an important role in agriculture ensuring proper harvest and crops (Figure 1). ${ }^{25} \mathrm{We}$ also cite the very recent discovery of the orally bioavailable compound 5 CNS penetrant negative allosteric modulator ${ }^{26}$ 


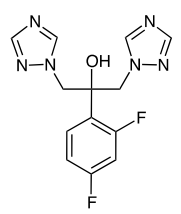

Fluconazole

1

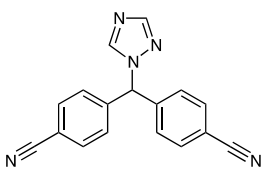

Letrozole<smiles>NC(=O)c1ncn(C2OC(CO)C(O)C2O)n1</smiles>

Ribarivin

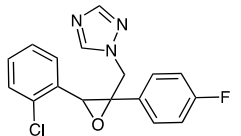

Epoxiconazole

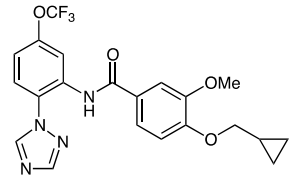

5

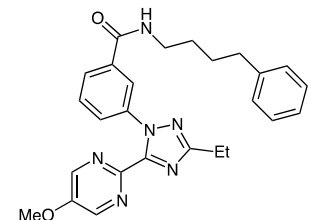

6

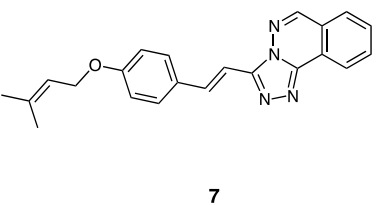

Figure 1. Triazoles with biological activities.

Table 1. Powder Parameters of Solid Auxiliaries without Grinding and after $15 \mathrm{~min}$ of Grinding in Parentheses

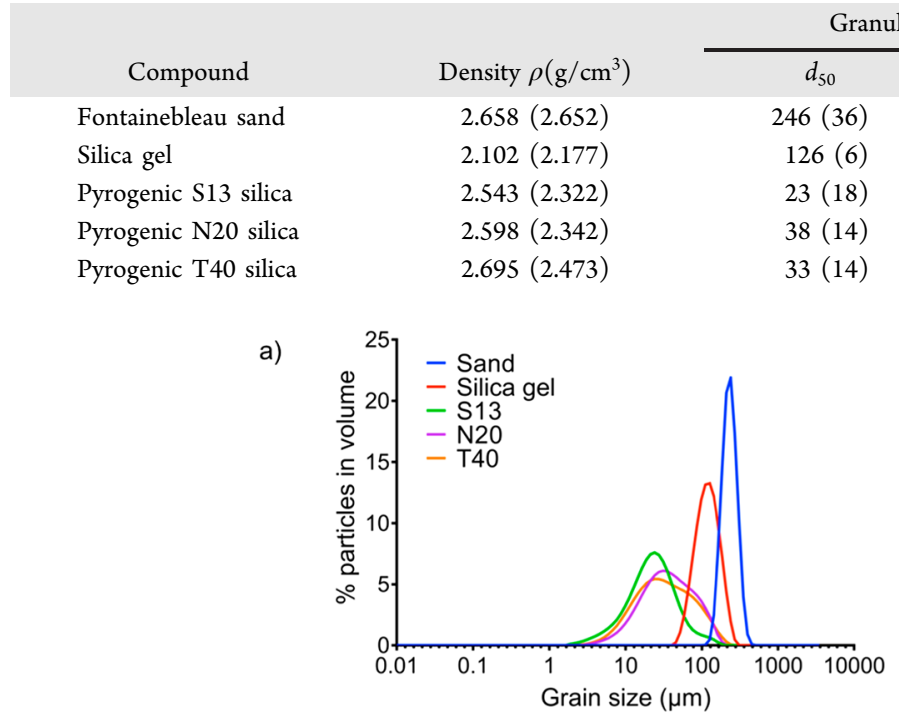

\begin{tabular}{|c|c|c|c|}
\hline \multicolumn{2}{|c|}{ Granulometry $(\mu \mathrm{m})$} & \multicolumn{2}{|c|}{ Specific surface area $\left(\mathrm{m}^{2} / \mathrm{g}\right)$} \\
\hline$d_{50}$ & $d_{3-2}$ & $a_{\mathrm{BET}}\left(\mathrm{N}_{2}\right)$ & $a_{\text {calculated }}($ eq 1$)$ \\
\hline$(36)$ & $240(4)$ & Too low (0.9) & $0.009(0.53)$ \\
\hline $6(6)$ & $118(3)$ & $456(419)$ & $0.02(0.86)$ \\
\hline (18) & $17(4)$ & $137(80)$ & $0.09(0.63)$ \\
\hline (14) & $23(4)$ & $196(162)$ & $0.09(0.55)$ \\
\hline (14) & $27(5)$ & $414(184)$ & $0.09(0.67)$ \\
\hline
\end{tabular}

Figure 2. Particle size distributions of solid auxiliaries (a) before and (b) after 15 min of grinding.
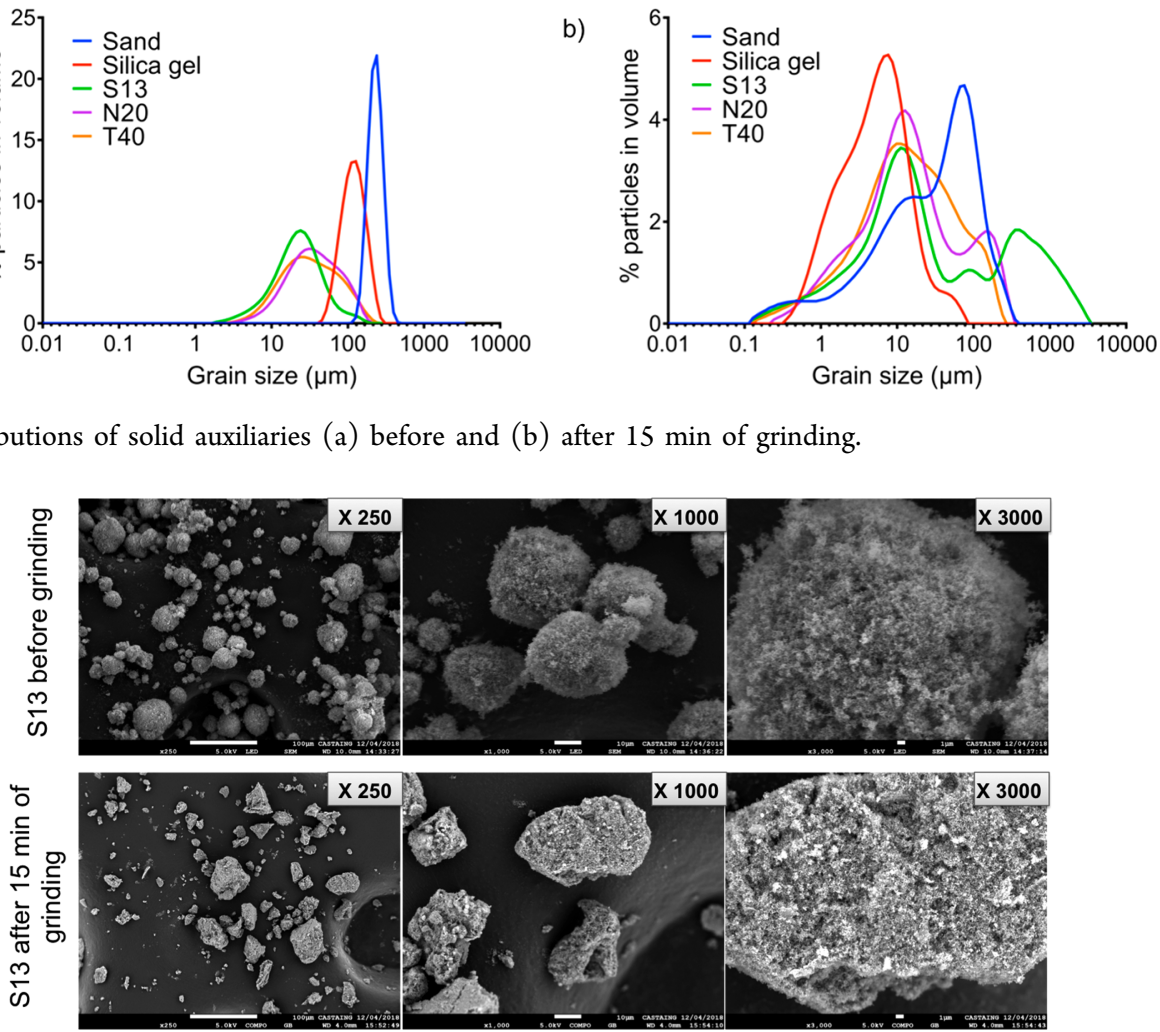

Figure 3. SEM analyses before (top) and after $15 \mathrm{~min}$ of grinding (bottom).

and also a series of 1,5-diaryl-1,2,4-triazole compounds 6 as novel agents against pancreatic cancer metastasis ${ }^{27}$ (Figure 1).

For some years now, we have explored the possibility of styryl annulated 1,2,4 triazoles derivatives as potential antituberculosis agents ${ }^{28,29}$ and found triazolophthalazine 7, with an excellent antitubercular potency $(\mathrm{MIC}=1.4 \mu \mathrm{M})$ in comparison with others, and more importantly, with good cytotoxicity toward HCT116 human cells $\left(\mathrm{IC}_{50}=449 \mu \mathrm{M} ; 160\right.$ $\mu \mathrm{g} / \mathrm{mL}$ and selectivity index $\mathrm{SI}=320)$.

Their extensive medicinal, agrochemical, and other potential applications have resulted in a major effort to develop synthetic methods that include three categories of synthetic objectives: 


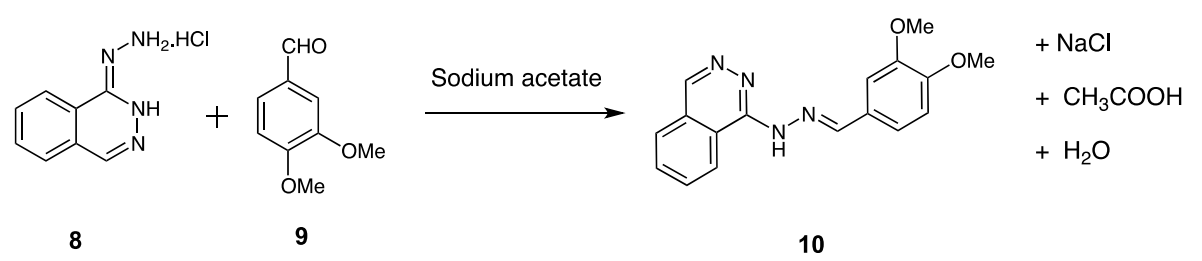

Figure 4. Synthesis of hydrazone 10 from hydralazine 8 and 3,4-dimethoxylbenzaldehyde 9.

(a) cyclizations to form the triazole ring, (b) transformations of heterocyclic compounds to construct the triazole ring, (c) substitutions on the 1,2,4 triazole ring (for recent reviews, see references 30 and 31).

Several years ago, we launched a research program in the area of mechanochemistry. ${ }^{32-34}$ One of the topics we focused on and reported about was the mechanochemical synthesis of various hydrazones ${ }^{35}$ and hydrazones bearing the isoniazide frame as potential antituberculosis agents. ${ }^{36}$ In addition, through the long-standing program concerning the conception and synthesis of new antituberculosis compounds, we found and developed annulated 1,2,4-triazoles as important compounds with new modes of action. ${ }^{28,29}$

In connection with these two programs, we report here the two steps and one-pot two-step mechanochemical synthesis of 1,2,4-triazoles from hydrazones, in the presence and absence of grinding auxiliaries.

Moreover, it is noteworthy to point out that there is only one reported synthesis of 1,2,4-triazole-fused heterocycles under electrochemical (green) conditions ${ }^{37}$ but no synthesis under mechanochemical ones.

\section{RESULTS AND DISCUSSION}

Surface Analyses of Grinding Auxiliaries. Grinding auxiliaries have been, since some years now, often used in

Table 2. Screening of Mechanochemical Conditions for the Synthesis of Hydrazone 10

\begin{tabular}{|c|c|c|c|c|c|}
\hline \multirow[b]{2}{*}{ Entry } & \multirow[b]{2}{*}{ Method } & \multirow[b]{2}{*}{$\begin{array}{l}\text { Time } \\
(\mathrm{min})\end{array}$} & \multicolumn{2}{|c|}{ Additive } & \multirow[b]{2}{*}{$\begin{array}{l}\text { Yielc } \\
(\%)\end{array}$} \\
\hline & & & Compound & $\begin{array}{l}\text { Grain size } d_{50} \\
(\mu \mathrm{m}) / \text { developed } \\
\text { surface }\left(\mathrm{m}^{2}\right)\end{array}$ & \\
\hline 1 & $\begin{array}{l}\text { EtOH, } \\
\quad \text { reflux }\end{array}$ & 60 & & & 100 \\
\hline 2 & $\begin{array}{l}\mathrm{P7}, \\
500 \mathrm{rpm}\end{array}$ & 15 & & & 43 \\
\hline 3 & $\begin{array}{l}\mathrm{P} 7, \\
500 \mathrm{rpm}\end{array}$ & $2 \times 15$ & & & 73 \\
\hline 4 & $\begin{array}{l}\mathrm{P7}, \\
500 \mathrm{rpm}\end{array}$ & $3 \times 15$ & & & 100 \\
\hline 5 & $\begin{array}{l}\mathrm{P} 7, \\
800 \mathrm{rpm}\end{array}$ & 15 & & & 46 \\
\hline 6 & $\begin{array}{l}\mathrm{P} 7, \\
\quad 800 \mathrm{rpm}\end{array}$ & $2 \times 15$ & & & 100 \\
\hline 7 & $\begin{array}{l}\mathrm{P} 7, \\
800 \mathrm{rpm}\end{array}$ & 15 & Sand & $246 / 0.005$ & 40 \\
\hline 8 & $\begin{array}{l}\mathrm{P} 7, \\
\quad 800 \mathrm{rpm}\end{array}$ & 15 & $\begin{array}{l}\text { Sand after } \\
15 \text { min } \\
\text { grinding }\end{array}$ & $37 / 0.5$ & 38 \\
\hline 9 & $\begin{array}{l}\mathrm{P} 7, \\
800 \mathrm{rpm}\end{array}$ & 15 & Silica gel & $126 / 228$ & 87 \\
\hline 10 & $\begin{array}{l}\mathrm{P} 7, \\
\quad 800 \mathrm{rpm}\end{array}$ & 5 & S13 silica & $23 / 68.5$ & 90 \\
\hline 11 & $\begin{array}{l}\mathrm{P} 7, \\
800 \mathrm{rpm}\end{array}$ & 15 & S13 silica & $23 / 68.5$ & 100 \\
\hline
\end{tabular}

organic mechanochemical synthesis. ${ }^{13,38-40}$ In this work, we focused on the use of three kinds of auxiliaries that are Fontainebleau sand, silica gel $(63-200 \mu \mathrm{m})$, and pyrogenic silicas HDK S13, N20, and T40 from the Wacker Company. Their physical properties were first examined. The aim was to determine parameters like their specific surface areas, granulometry, and density before and after $15 \mathrm{~min}$ of grinding, which is the grinding time for most of our experiments (Table 1).

A very weak change of the densities of the auxiliaries is observed after $15 \mathrm{~min}$ of grinding. For sand and silica gel, the modification is less than $4 \%$, while for pyrogenic silicas, the decrease after grinding attains $10 \%$ (Table 1).

With regard to granulometry measurements, dry dispersions at 0.5 bar have been used. Median diameters $\left(d_{50}\right)$ and Sauter mean diameters $\left(d_{3-2}\right)$ were determined before and after grinding, and values are reported in Table 1.

The effects of grinding included the drastic decrease of $d_{50}$ for sand and silica gel indicating that the energy upon grinding can dramatically modify their granulometry. This is not the case for the pyrogenic silicas, which already have a low grain size before grinding. The particle size distributions were also determined and presented in Figure 2.

As we can see, for all the grinding auxiliaries used, the solid particle size distribution became less homogeneous after grinding. This is especially the case for pyrogenic silicas where the diameter of the particle agglomerates can vary between 12 and $310 \mu \mathrm{m}$ for pyrogenic N20 and T40 silicas and between 12 and $3000 \mu \mathrm{m}$ for pyrogenic S13 silica. It seems likely that grinding transforms pyrogenic silicas to smaller particles but also consolidates larger agglomerates.

Specific surfaces areas were measured by nitrogen adsorption at $77 \mathrm{~K}$ and application of the BET equation and were also calculated after determination of the density and the particle diameter $d_{3,2}$. In this latter case, the specific surfaces take only into account spherical particles without pores. The specific surface area calculation is indicated in eq 1

$$
a_{\text {calculated }}=\frac{6}{\rho \times d_{3,2}}
$$

The specific surface area of sand before grinding cannot be determined while after grinding, the BET equation gave an approximate value of $0.9 \mathrm{~m}^{2} / \mathrm{g}$. This value is close to the calculated one $\left(0.53 \mathrm{~m}^{2} / \mathrm{g}\right)$; indeed, we can consider sand as a spherical particle without pores. For silica gel and pyrogenic silicas, large variations between BET and calculation were observed. Indeed, silica gel is known as a mesoporous material and pyrogenic silicas are constituted of primary particles aggregates, which provide an important specific surface area.

After grinding, a smaller surface was calculated for sand. Indeed, the granulometry decreases sharply after $15 \mathrm{~min}$ of grinding ( $246 \mu \mathrm{m}$ before grinding and $37 \mu \mathrm{m}$ after grinding), thus increasing the specific surface area calculated. Finally, with 


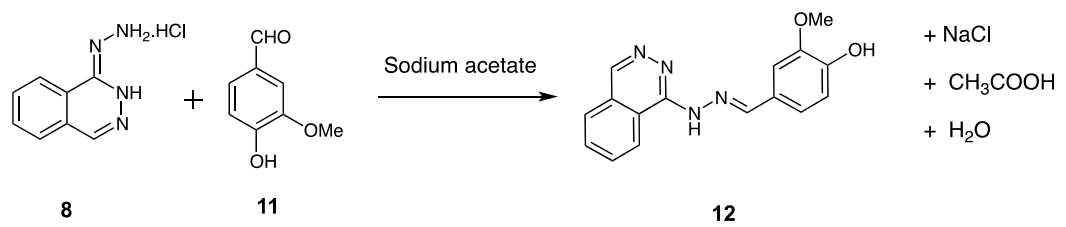

Figure 5. Synthesis of hydrazone $\mathbf{1 2}$ from hydralazine $\mathbf{8}$ and vanillin $\mathbf{1 1}$.

Table 3. Screening of Mechanochemical Conditions for the Synthesis of Hydrazone 12

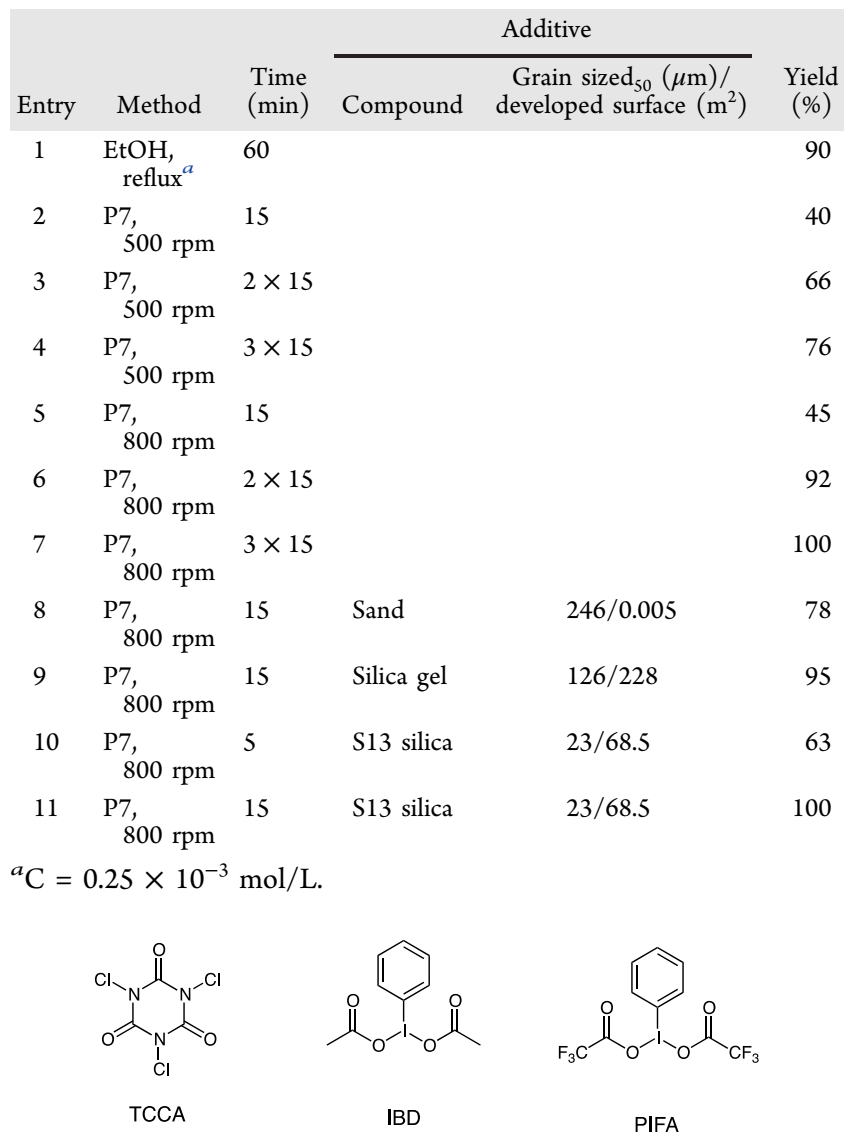

Figure 6. Cycling agents: TCCA, IBD, and PIFA.

the $S_{\mathrm{BET}}$ surfaces, there is a very weak decrease after $15 \mathrm{~min}$ of grinding for the silica gel ( $8 \%$ ) while a very important one for the pyrogenic silicas (41\%) (Table 1). Indeed, pyrogenic silicas are in the form of aerated agglomerates and these agglomerates can be compacted during grinding.

MEB analyses of the S13 silica before and after $15 \mathrm{~min}$ of grinding are in agreement with our previous assumption of compaction (Figure 3). In fact, they show clearly the morphology that is porous and spacious having the appearance of a grape before grinding. After $15 \mathrm{~min}$ of grinding, the
Table 4. Screening of Mechanochemical Conditions for the Synthesis of Triazole 13 Using TCCA

\begin{tabular}{cccrc} 
& & & \multicolumn{2}{c}{ Yield (\%) } \\
\cline { 4 - 5 } Entry & equiv TCCA & Time $(\min )$ & 13 & 14 \\
1 & 1 & 15 & 3 & 35 \\
2 & 0.1 & 15 & 30 & $<5$ \\
3 & $4 \times 0.1$ & $4 \times 10$ & 18 & 15
\end{tabular}

morphology becomes quite different; the grapes are much more compacted and less spacious; nevertheless, the size of the individual particles remains the same as also indicated by the granulometric measurements.

Synthesis of Hydrazones. We reported in 2014 (Oliveira et al.), our first results concerning the synthesis of hydrazones by mechanochemical means using the vibratory mill Pulverisette 0 (P0) (Fritsch, Germany) ${ }^{35}$ and reacting a suitable aldehyde with selected hydrazines in an equimolar ratio. In most of the cases, mechanochemical synthesis afforded hydrazones in very good to quantitative yields after $2-4 \mathrm{~h}$ of reaction. The syntheses of hydrazones by solid-solid techniques including mechanochemical ones have already been reported by various groups. ${ }^{41,42}$

In the study reported here, we focused on the synthesis of hydrazones starting from hydralazine hydrochloride and reacting it with various aldehydes. Hydralazine hydrochloride was used because the corresponding hydrazones might cyclize in a second step to afford the annulated 1,2,4-triazoles.

A planetary ball-mill, Pulverisette 7 (P7) (Fritsch, Germany) bearing $20 \mathrm{~mL}$ jars and five balls in zirconium oxide $(10 \mathrm{~mm}$ diameter, $14.7 \mathrm{~g}$ for 5 balls), was used. Model studies were first run with 3,4-dimethoxybenzaldehyde and vanillin. The reaction was conducted in the presence of sodium acetate, on a $5 \mathrm{mmol}$ scale with or without three types of grinding auxiliaries including Fontainebleau sand, silica gel, and various pyrogenic silicas.

Synthesis from 3,4-Dimethoxybenzaldehyde. First, the reaction between hydralazine 8 and 3,4-dimethoxybenzaldehyde 9 (Figure 4) in the presence of sodium acetate ( 1 equiv each) was conducted under several conditions (Table 2).

The conventional reaction was conducted in $\mathrm{EtOH}$ solution under reflux and followed by TLC. Total conversion was observed after $1 \mathrm{~h}$ of reaction (Table 2 , entry 1 ). By using mechanochemical means, we first modified two parameters, i.e., the rotation speed and the time of reaction with a sequence<smiles>COc1ccc(/C=N/Nc2nncc3ccccc23)cc1OC</smiles>

Figure 7. Cyclization of hydrazone 10 using TCCA. 


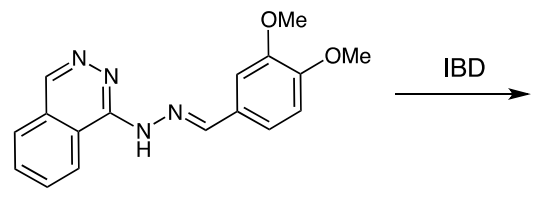

10

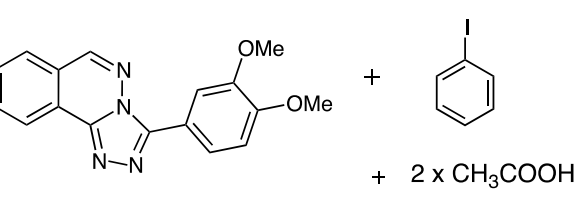

13

Figure 8. Cyclization of hydrazone 10 using IBD.

Table 5. Screening of Mechanochemical Conditions for the Synthesis of Triazole 13 Using IBD

\begin{tabular}{|c|c|c|c|c|c|}
\hline \multirow[b]{2}{*}{ Entry } & \multirow[b]{2}{*}{ Method } & \multirow[b]{2}{*}{$\begin{array}{l}\text { Time } \\
(\mathrm{min})\end{array}$} & \multicolumn{2}{|r|}{ Additives } & \multirow[b]{2}{*}{$\begin{array}{l}\text { Yield } \\
(\%)\end{array}$} \\
\hline & & & Compound & $\begin{array}{c}\text { Grain size } d_{50}(\mu \mathrm{m}) / \\
\text { developed surface } \\
\left(\mathrm{m}^{2}\right)\end{array}$ & \\
\hline 1 & $\mathrm{CH}_{2} \mathrm{Cl}_{2}{ }^{a}$ & 240 & & & 84 \\
\hline 2 & $\begin{array}{l}\mathrm{P} 7 \\
\quad 800 \mathrm{rpm}\end{array}$ & 15 & & & 68 \\
\hline 3 & $\begin{array}{l}\text { P7, } \\
\quad 800 \mathrm{rpm}\end{array}$ & $3 \times 15$ & & & 97 \\
\hline 4 & $\begin{array}{l}\mathrm{P} 7 \\
\quad 800 \mathrm{rpm}\end{array}$ & 15 & Sand & $246 / 0.005$ & 63 \\
\hline 5 & $\begin{array}{l}\mathrm{P} 7 \\
\quad 800 \mathrm{rpm}\end{array}$ & 15 & Silica gel & $126 / 228$ & 73 \\
\hline 6 & $\begin{array}{l}\mathrm{P} 7, \\
800 \mathrm{rpm}\end{array}$ & 15 & S13 silica & $23 / 68.5$ & 93 \\
\hline
\end{tabular}

Table 6. Impact of Silica Developed Surface

\begin{tabular}{cccccc} 
& \multicolumn{5}{c}{ Pyrogenic silicas } \\
\cline { 2 - 5 } Entry & Type & $\begin{array}{c}\text { Wt } \\
(\mathrm{mg})\end{array}$ & $\begin{array}{c}\text { Specific surface } \\
\left(\mathrm{m}^{2} / \mathrm{g}\right)\end{array}$ & $\begin{array}{c}\text { Developed surface } \\
\left(\mathrm{m}^{2}\right)\end{array}$ & $\begin{array}{c}\text { Yield } \\
(\%)\end{array}$ \\
1 & & & & 68 & 68 \\
2 & $\mathrm{~S} 13$ & 500 & 137 & 68 & 93 \\
3 & $\mathrm{~N} 20$ & 350 & 196 & 68 & 85 \\
4 & $\mathrm{~T} 40$ & 170 & 414 & 207 & 92 \\
5 & $\mathrm{~T} 40$ & 500 & 414 & & 82
\end{tabular}

of $15 \mathrm{~min}$ and then a $5 \mathrm{~min}$ pause followed by another cycle. After sampling, all reactions were followed immediately by ${ }^{1} \mathrm{H}$ NMR $\left(\mathrm{CDCl}_{3}\right)$. For $15 \mathrm{~min}$ of reaction, we observe almost identical conversions of $43 \%$ and $46 \%$ with rotation speeds of 500 and $800 \mathrm{rpm}$ respectively (Table 2 , entries 2,5 ). While operating at longer periods $(2 \times 15 \mathrm{~min})$, a quantitative conversion was attained when running the reaction at $800 \mathrm{rpm}$, and a much lesser one ( $73 \%$ of conversion) was obtained when operating at $500 \mathrm{rpm}$. (Table 2, entries 6, 3, respectively). Finally, the conversion is quantitative at $500 \mathrm{rpm}$ after 3 cycles of $15 \mathrm{~min}$ (Table 2, entry 4 ). The same reaction was then conducted in the presence of grinding auxiliaries $(500 \mathrm{mg})$. Aldehyde 9 was first adsorbed on the grinding auxiliary. The rotation speed was maintained at $800 \mathrm{rpm}$ (Table 2, entries 711). Sand (ground or not ground alone) gave the same results than those without auxiliary grinding (Table 2, entries 5, 7, 8). Indeed, sand does not adsorb water, acetic acid was generated during the reaction, and its grain size sharply decreased by grinding ( $246 \mu \mathrm{m}$ before grinding and $37 \mu \mathrm{m}$ after grinding, Table 1). So, part of the energy provided by the balls is used to reduce the size of the sand grains and not for the reaction. The use of silicas provides better yields than sand. While silica gel afforded $87 \%$ conversion after 15 min of milling, pyrogenic S13 afforded excellent conversion after $5 \mathrm{~min}$ of milling and a quantitative one after 15 min of milling (Table 2, entries 9, 10,
11). These better results, in comparison to sand auxiliary, can be explained by the capacity of silicas to adsorb water and acetic acid. Moreover, like sand, the granulometry of silica gel was sharply decreased (126 $\mu \mathrm{m}$ before grinding and $11 \mu \mathrm{m}$ after grinding, Table 1) contrary to that of pyrogenic S13 silica (23 $\mu \mathrm{m}$ before grinding and $18 \mu \mathrm{m}$ after grinding, Table 1 ). So, the energy provided by balls was also used to grind silica gel and to a much lesser extent for S13. We can observe that the yield increases with a smaller grain size of grinding auxiliaries that is not affected by milling. In regard to these results, we can hypothesize that grinding auxiliaries can report the energy of the balls on the reactant powder without loss of energy and thus produce a faster reaction. Moreover, the developed surface of grinding auxiliaries does not seem to have an effect on the reaction. Indeed, a better yield was obtained with pyrogenic silica $\left(68.5 \mathrm{~m}^{2}\right)$ than with silica gel $\left(228 \mathrm{~m}^{2}\right)$ (Table 2 , entries 9,11$)$. The reaction was conducted as before (Table 2 , entry 11). The solid material was washed with $\mathrm{CH}_{2} \mathrm{Cl}_{2}$, filtered. and dried to eliminate organic molecules. Particles size distribution measurements were carried out (see SI, page S10, Figure S1) and compared with those of pyrogenic silica S13 before milling and after $15 \mathrm{~min}$ of milling. However, it is noteworthy that the purifying post treatment of pyrogenic S13 silica may modify the surface properties and consequently alter the observed agglomerates. This is the reason why a deeper interpretation could be hazardous.

Synthesis from Vanillin. The same study was conducted with vanillin 11 (Figure 5, Table 3).

Results of the reactions in the absence of grinding auxiliary and with varying, respectively, the rotation speed and the time of milling are presented in Table 3. The reaction is slower than that with 3,4-dimethoxybenzaldehyde 9.

Conversions at low rotation speed $(500 \mathrm{rpm})$ are between $40 \%$ and $76 \%$ after $15 \mathrm{~min}$ to $3 \times 15 \mathrm{~min}$ of milling (Table 3 , entries 2, 3, 4). For a higher speed of rotation, three cycles of $15 \mathrm{~min}$ of milling are necessary to obtain quantitative conversion (Table 3, entry 7 ). The same reaction was then conducted in the presence of grinding auxiliaries as was done previously. The rotation speed was maintained at $800 \mathrm{rpm}$. In all cases, we observe an increase in the conversion to hydrazone. As before, this is especially the case with the pyrogenic S13 silica where a total conversion is obtained after $15 \mathrm{~min}$ of grinding, for the same reasons mentioned before (Table 3, entry 11). As previously observed, an increase of developed surface does not accelerate the reaction (Table 3, entries 9, 11).

Synthesis of Annulated 1,2,4-Triazoles. Intramolecular cyclization of hydrazones to form 1,2,4-heterocyclic systems has been reported in the literature, most often by the use of three oxidizing agents: trichloroisocyanuric acid (TCCA), ${ }^{43,44}$ iodobenzene diacetate (IBD), ${ }^{45,46}$ or its fluorinated analogue phenyl iodine bis(trifluoroacetate) (PIFA) ${ }^{47,48}$ (Figure 6). 


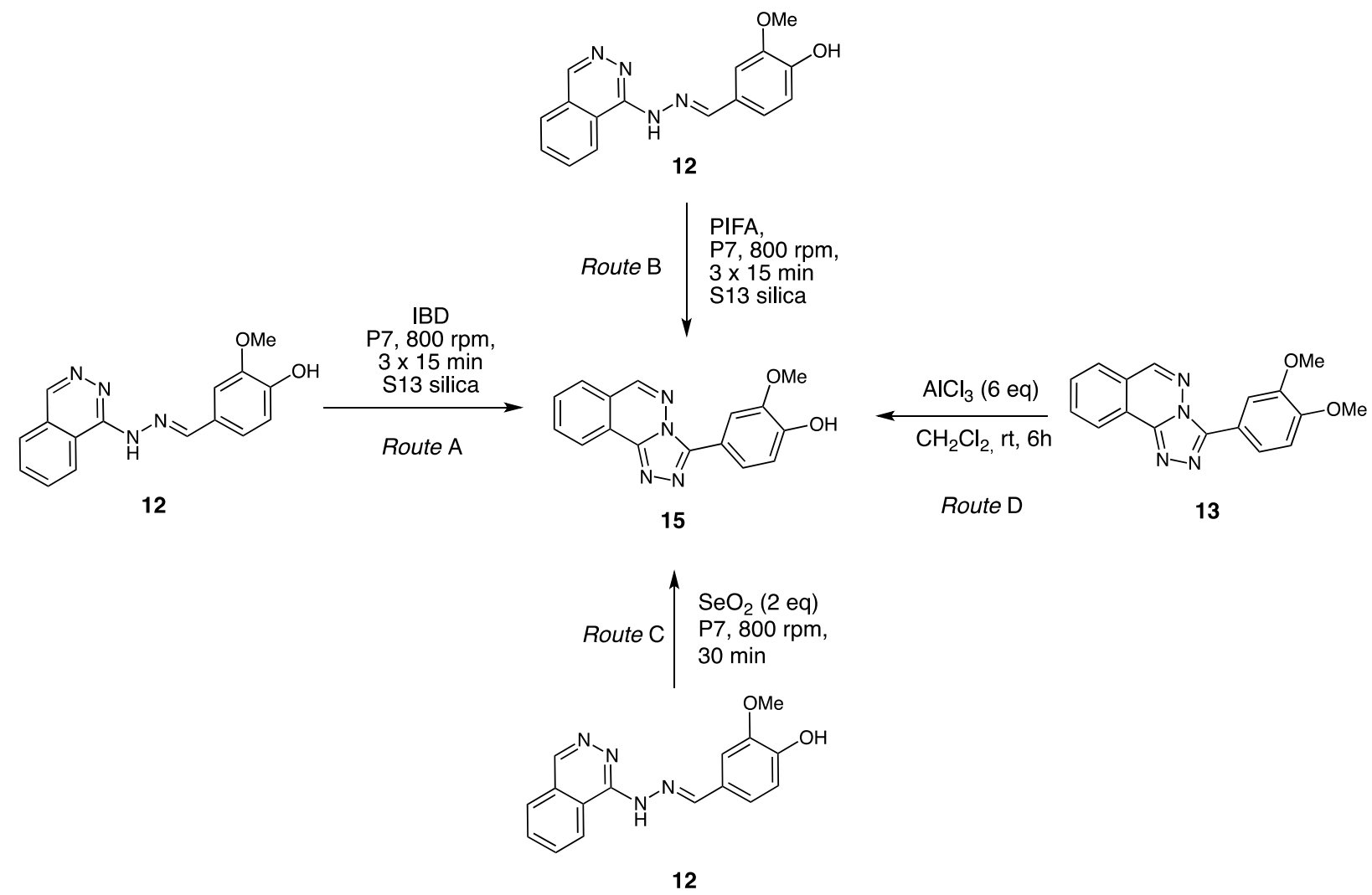

Figure 9. Different routes for the triazole 15 synthesis.

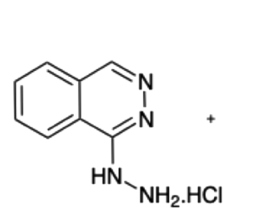

8

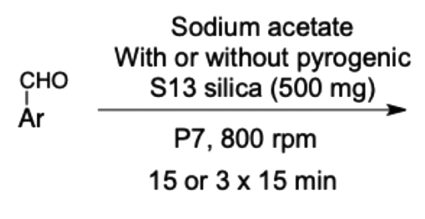

P7, $800 \mathrm{rpm}$
15 or $3 \times 15 \mathrm{~min}$

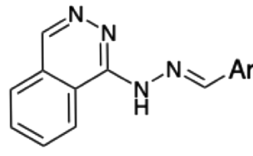

$10,16 a-22 a$

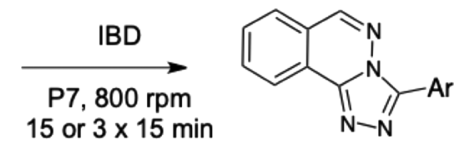

$13,16 b-22 b$

Figure 10. One-pot two-step procedure for the synthesis of 1,2,4-triazoles $\mathbf{1 3}, \mathbf{1 6} \mathbf{b}-\mathbf{2 2} \mathbf{b}$.

We first checked the reaction between hydrazone $\mathbf{1 0}$ and TCCA under mechanochemical conditions at $800 \mathrm{rpm}$ (Figure 7). Results are reported in Table 4.

When using 1 equiv of TCCA, with a rotation speed of 800 rpm, we observe, after 15 min of milling, the disappearance of the starting hydrazones. Among the complex mixture, we could purify and identify two compounds: the desired triazole 13 obtained in $3 \%$ yield and the monochlorinated triazole $\mathbf{1 4}$ in $35 \%$ yield (Table 4 , entry 1 ). Extensive NMR analysis showed that the chlorine atom was introduced at the 6 position of the dimethoxy aryl fragment.

When using 0.1 equiv of TCCA under the same conditions, we obtain, after careful purification, the desired 1,2,4-triazole 13 in $30 \%$ yield along with a small amount of the same monochlorinated compound $\mathbf{1 4}$ (Table 4, entry 2). Finally, when we introduce 0.1 equiv of TCCA every $10 \mathrm{~min}$ of milling and stop the reaction after $40 \mathrm{~min}$ of milling, we again obtain, after careful purification, compounds 13 and 14 in $18 \%$ and $15 \%$ yields respectively (Table 4 , entry 3 ).

TCCA acts just like a chlorinating agent and therefore is not a good choice to obtain desired triazoles. This major drawback was also reported by Sniady et al. ${ }^{44}$
Next, we tried IBD as the oxidizing agent for the cyclization of hydrazone 10 (Figure 8). Different reaction conditions under mechanochemical means were tested along with the conventional reaction in solution, by using 1 equiv of IBD (Table 5).

The reaction in dichloromethane (DCM) at room temperature afforded, after $4 \mathrm{~h}$, the triazole 13 in $84 \%$ yield after purification (Table 5, entry 1 ).

The mechanochemical reaction leads to triazole 13 in $68 \%$ yield after 15 min of milling and in the absence of any auxiliary. Excellent conversion was obtained after $3 \times 15$ min of grinding (Table 5, entries 2, 3). While sand as grinding auxiliary gave comparable result (63\% yield), silica had an increase of yield $(73 \%)$ as a consequence (Table 5, entries 4, 5). Again, gratifyingly, pyrogenic silica S13 gave the best result (Table 5, entry 6). After $15 \mathrm{~min}$ of milling, triazole 13 was obtained in 93\% yield after purification.

A brief insight in the role of silicas was attempted through the following experiments: hydrazone $\mathbf{1 0}$ was allowed to react with one equivalent of IBD in the presence of pyrogenic grinding auxiliaries where we modified either the weighted mass or the developed surface of the auxiliaries. Pyrogenic S13, $\mathrm{N} 20$, and T40 have the same nature as silicas and almost 
Table 7. One-Pot Two-Step Procedure for the Synthesis of Triazoles 13, 16b-22b

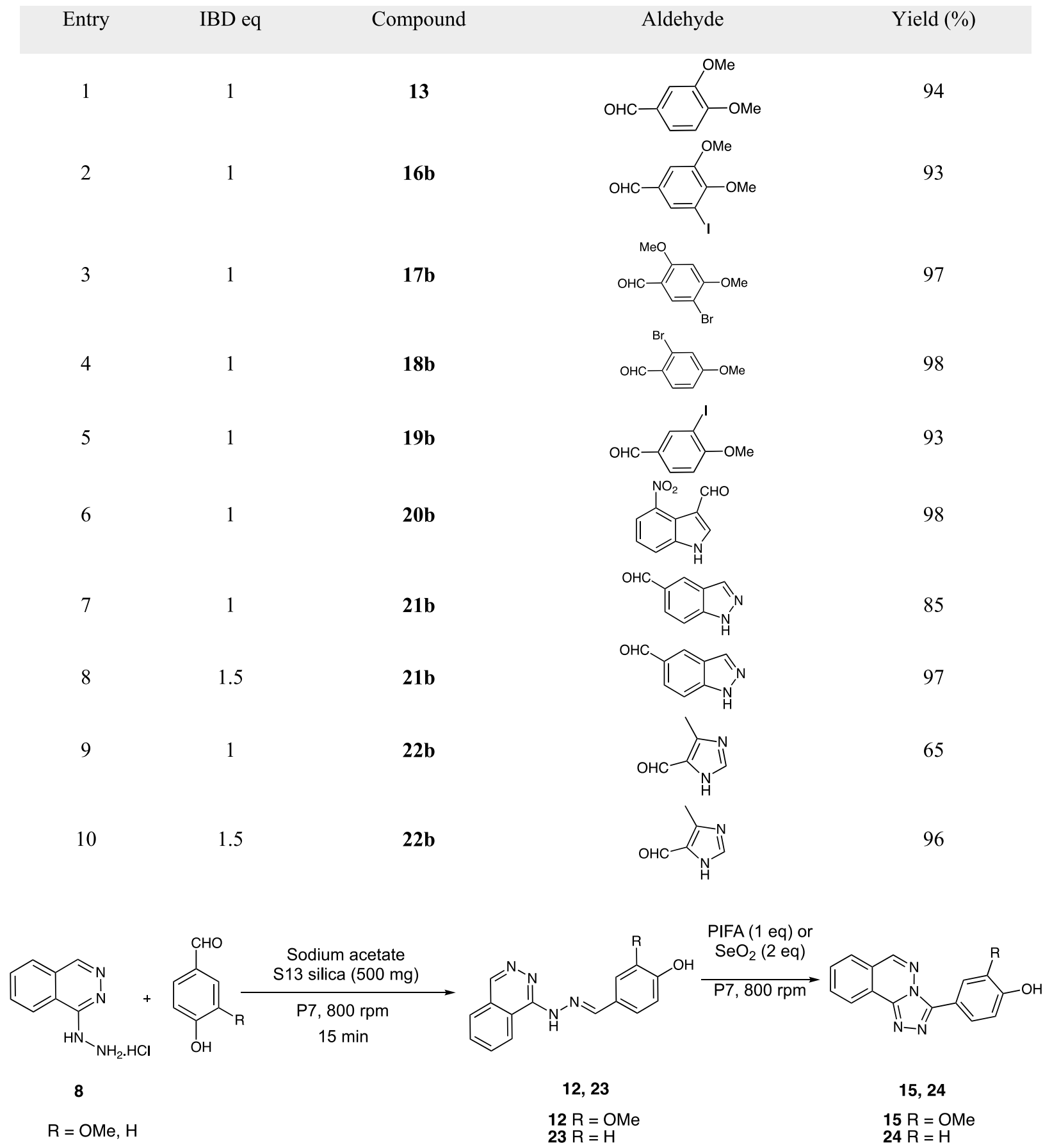

Figure 11. One-pot two-step synthesis for the formation of 1,2,4-triazole 15 and 24.

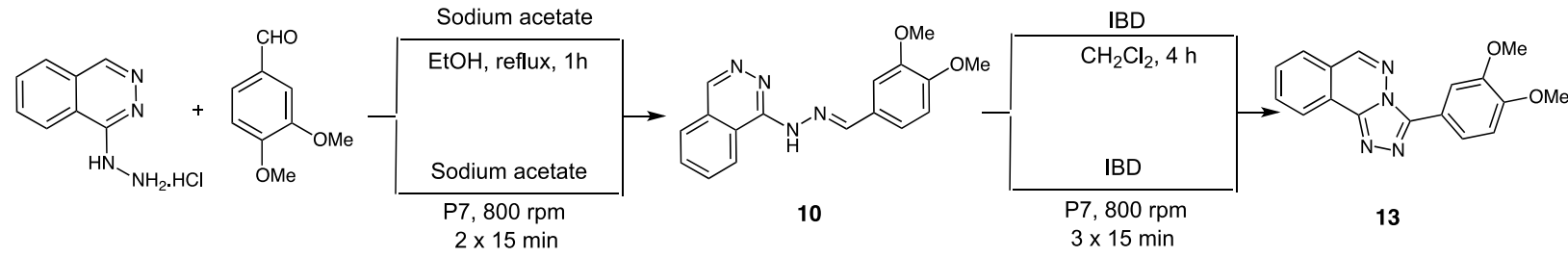

Figure 12. Comparison of the two-step procedure reactions in solution and using mechanochemistry.

identical granulometry but different specific surface areas. Mechanochemical reaction was conducted for $15 \mathrm{~min}$ at 800 rpm; results are presented in Table 6.
Equivalent yields of compound $\mathbf{1 3}$ (93\% and 92\%, Table 6, entries 2,5) are obtained when using the same weight $(500$ $\mathrm{mg}$ ) but different developed surface areas of silica S13 and T40 
Table 8. Comparative Green Metrics for the Synthesis of Hydrazone 10 and Triazole 13, in Solution/by Mechanochemistry

$\begin{array}{cclcc}\text { Compound } & \text { Time }(\mathrm{h}) & \text { Yield }(\%) & \text { E-factor } & \text { PMI } \\ \mathbf{1 0} & 1 / 0.5 & 100 / 100 & 14 / 4 & 15 / 5 \\ 13 & 4 / 0.75 & 84 / 97 & 74 / 12 & 75 / 13\end{array}$

(68 and $207 \mathrm{~m}^{2}$, respectively). This indicates that the developed surface does not have any effect on the reaction, with regard to better adsorption by products (acetic acid). When using the same developed surface $\left(68 \mathrm{~m}^{2}\right)$ but different silica weight (170 to $500 \mathrm{mg}$, Table 6 , entries $2,3,4$ ), the yields obtained are lower when decreasing the silica weight. In regard to these results, we could propose that silicas might only have a mechanical effect upon the reaction progress by a more efficient transfer of the mechanical energy from the balls to the reactants.

With regard to the cyclization of hydrazone issued from vanillin and bearing a free hydroxy group, the reaction appeared much more tedious (Figure 9).

While TCCA gave an inseparable mixture of many compounds, IBD or PIFA reagents operate very poorly giving, after purification, less than $8 \%$ of triazole 15 along with many other nonisolable compounds (Figure 9, route A and B). After various unsuccessful attempts, we were satisfied to find two methods in order to obtain the phenolic triazole 15. The first one makes use of the potential demethylation at the para position of the triazole 13 issued from 3,4-dimethoxybenzaldehyde 9 (Figure 9, route D). In fact, when using 6 equiv of $\mathrm{AlCl}_{3}$ in the presence of triazole 13 in methylene chloride, we obtain, after $6 \mathrm{~h}$ of reaction at room temperature, careful work up, and purification, the desired triazole 15 in $60 \%$ yield. Most gratifyingly, by using 2 equiv of selenium dioxide in the presence of phenolic hydrazone $\mathbf{1 2}$ under mechanochemical conditions for $30 \mathrm{~min}$ we obtain the cyclized compound, phenolic 1,2,4-triazole 15 in $75 \%$ yield (Figure 9, route C).
One-Pot Two-Step Synthesis of C-3 Substituted 1,2,4-Triazoles. After having successfully studied the mechanochemical synthesis of hydrazones 10 and 12 and their corresponding triazoles $\mathbf{1 3}$ and $\mathbf{1 5}$ in a sequential twostep procedure, we attempted the one-pot two-step reaction (Figure 10). The attempt became possible and was successful as the grinding auxiliary for the optimized reactions in each step is the same and initial reagent (sodium acetate) does not affect the second step.

Hydralazine hydrochloride 8 and 3,4-dimethoxybenzaldehyde 9 were reacted together in the presence of sodium acetate and pyrogenic S13 silica for $15 \mathrm{~min}$; hydrazone 10 obtained quantitatively was then reacted with IBD for $15 \mathrm{~min}$ in a onepot two-step procedure. The desired annulated 1,2,4-triazole 13 was thus obtained in $94 \%$ overall yield (Table 7 , entry 1).

The same reaction, when run for $15 \mathrm{~min}$ for each step, with different nonphenolic aromatic aldehydes afforded the corresponding triazoles 16-19 in excellent yields, varying between $93 \%$ and $98 \%$ after two steps (Table 7, entries 2-5). Hydrazones were always obtained in quantitative yield.

Heteroaromatic aldehydes were also allowed to react with hydralazine hydrochloride 8. After some conditions were adjusted due to the insolubility of the final heteroaromatic triazoles 20-22, we found that the best way to obtain them is without any grinding auxiliary and in the presence of 1 or 1.5 equiv of IBD (Table 7, entries 6-10). Under these conditions, after $3 \times 15$ min of milling for each step and water washing of the crude material, excellent yields of annulated heteroaromatic 1,2,4-triazoles 20-22 were obtained (96-98\%).

Finally, the one-pot two-step sequence was also applied for two phenolic aldehydes, i.e., $p$-hydroxy-benzaldehyde and vanillin 11 (Figure 11).

The one-pot two-step reaction was conducted in the presence of either 2 equiv of selenium dioxide or 1 equiv of PIFA. When using $\mathrm{SeO}_{2}$ and after $30 \mathrm{~min}$ of milling, we obtained triazole 15 in $70 \%$ yield and triazole 24 in $40 \%$. The reactions in the presence of PIFA were much less efficient,
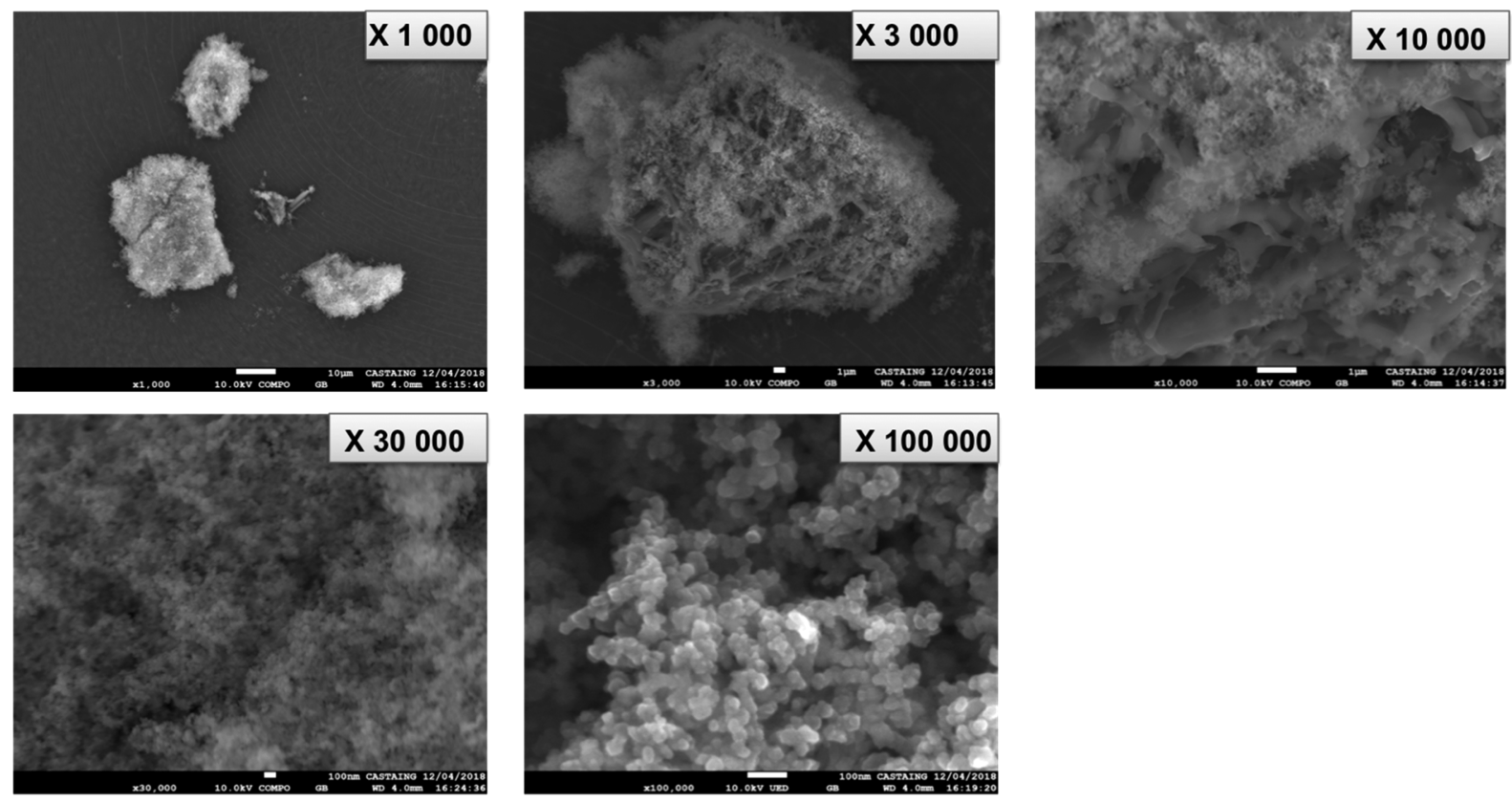

Figure 13. SEM analyses of hydrazone 10 adsorbed on pyrogenic S13 silica. 

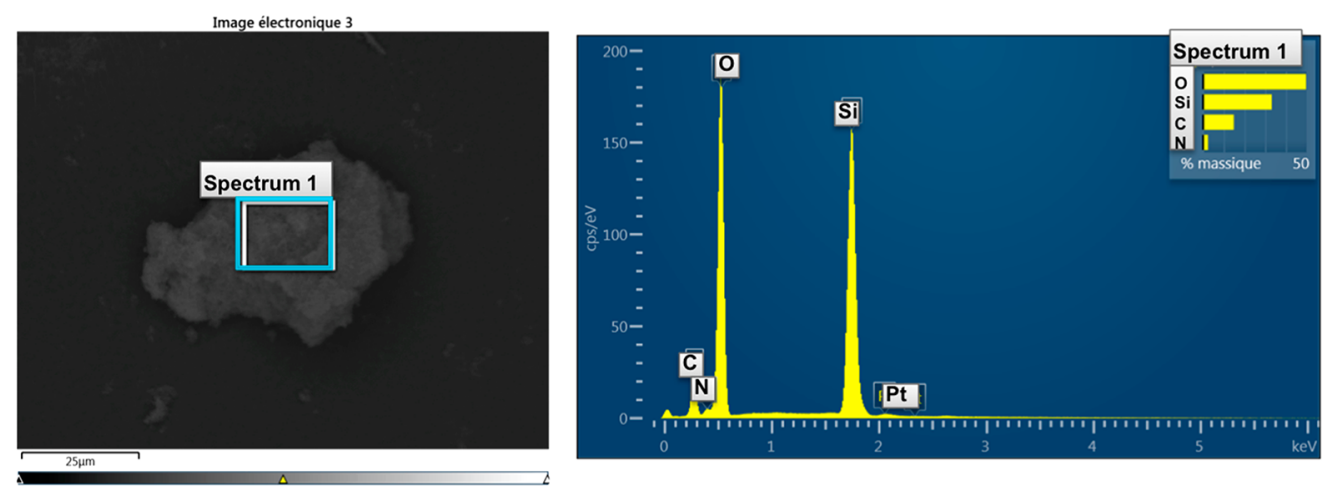

Figure 14. EDS probe of hydrazone 10 adsorbed on pyrogenic S13 silica.
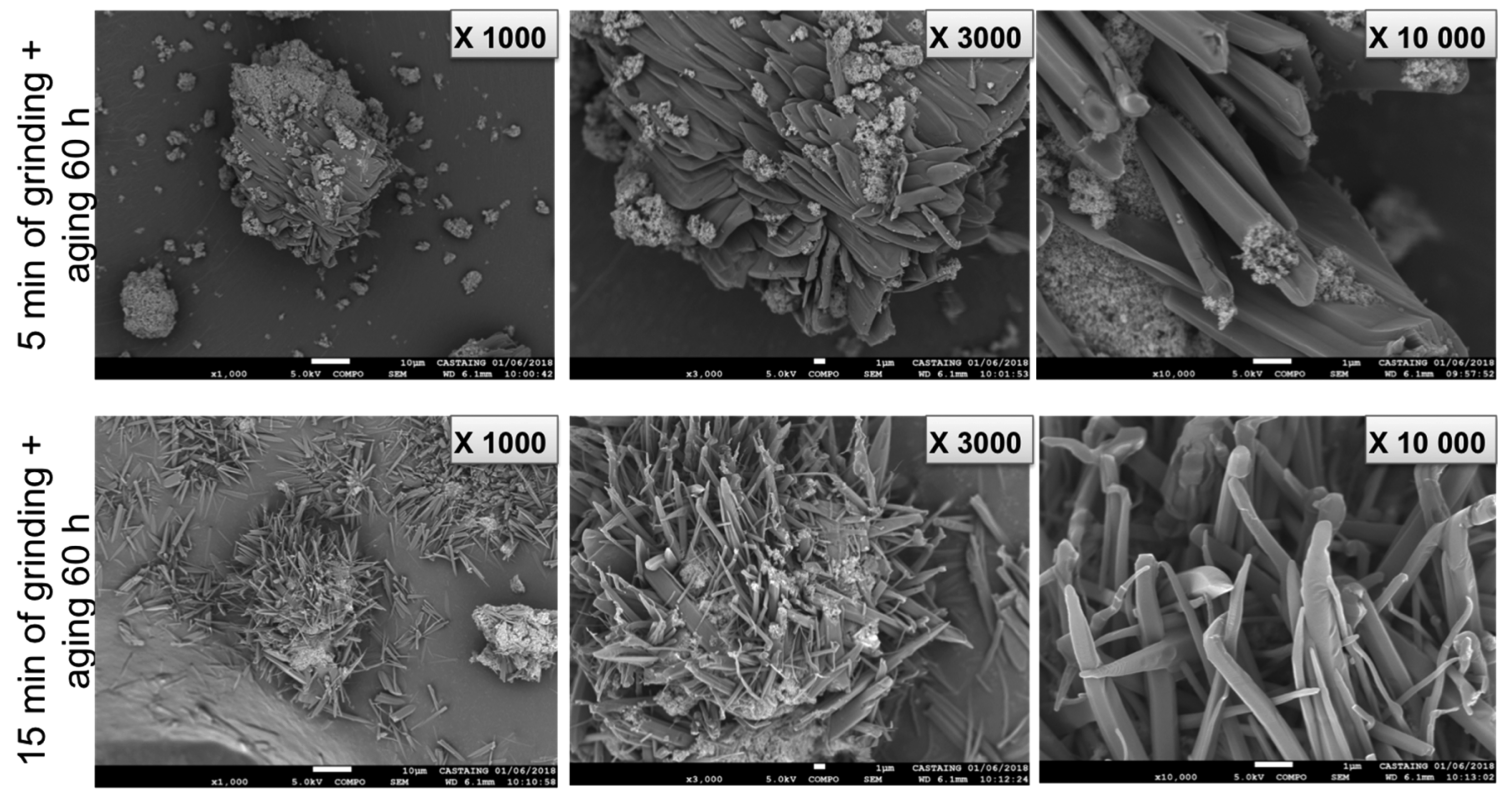

Figure 15. SEM analyses of triazole 13 adsorbed on pyrogenic S13 silica after $5 \mathrm{~min}$ (top) and 15 min of grinding (bottom) and after $60 \mathrm{~h}$ of aging.
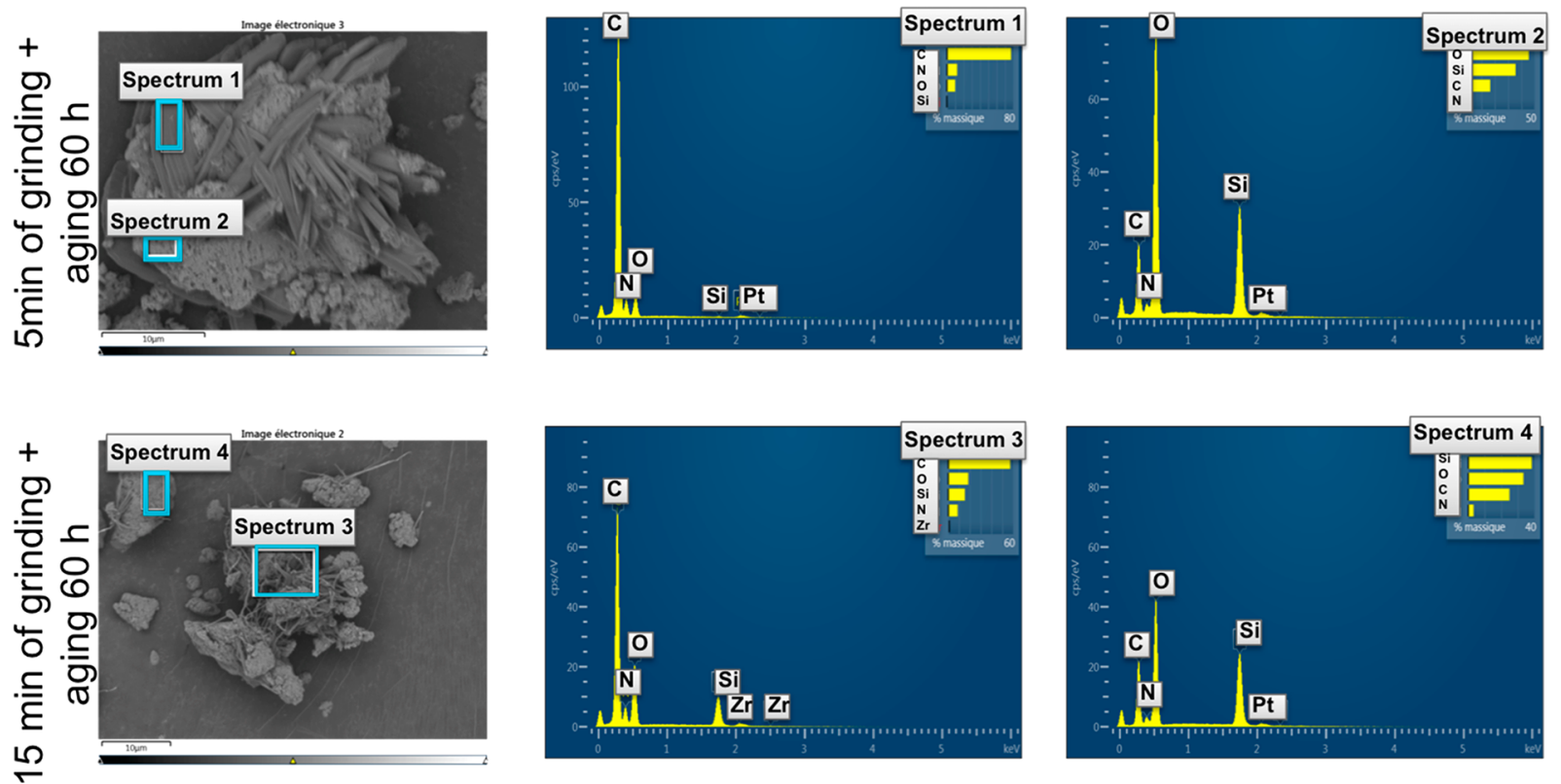

Figure 16. EDS probe of triazole 13 adsorbed on pyrogenic S13 silica. 
leading to triazoles $\mathbf{1 5}$ and $\mathbf{2 4}$ in $8 \%$ and $12 \%$ of yield, respectively, after $3 \times 15$ min of grinding (Figure 11).

Green Metrics. In solution, syntheses of compounds $\mathbf{1 0}$ and 13 were conducted only in a two-step procedure. So, in order to evaluate and benchmark the more sustainable process, we compared it with the two-step mechanochemical method without grinding auxiliary (Figure 12).

Calculations of the green chemistry metrics for both procedures were performed.

The environmental factor, $E$-factor, which is defined in eq $2^{1,4}$

$$
E \text {-factor }=\frac{\text { mass of total waste }(\mathrm{kg})}{\text { mass of product }(\mathrm{kg})}
$$

And the process mass intensity (PMI), which is defined in eq $3^{4}$

$$
\mathrm{PMI}=\frac{\text { total mass used in the process }(\mathrm{kg})}{\text { mass of product }(\mathrm{kg})}=E \text {-factor }-1
$$

The results are presented in Table 8 .

While metrics such as carbon economy, $\mathrm{CE}^{4}$ (0.89 for $\mathbf{1 0}$ and 0.63 for 13 in solution and using P7), atom economy, $\mathrm{AE}^{4}$ (0.69/0.69 for 10 and $0.49 / 0.49$ for 13 in solution/using P7), and reaction mass efficiency, $\mathrm{RME}^{4}(0.69 / 0.69$ for $\mathbf{1 0}$ and $0.41 / 0.47$ for 13 in solution/using P7) are essentially the same between the mechanochemical and solvent-based procedures. The E-factor and the PMI metrics were better with the use of P7 compared to those of the reactions in solution thanks to the solvent reduction (Table 7). Detailed calculations are reported in Supporting Information.

SEM Analyses in the Presence of Products. SEM images were also taken for reactions with the pyrogenic S13 silica in two different cases: (i) in the presence of compound 10 once obtained and adsorbed and (ii) with triazole 13 after the mechanochemical reaction of hydrazone 10 with IBD in order to obtain it.

Hydrazone 10 when adsorbed in S13 gave SEM images presented in Figure 13. The morphology of S13 is the same as when no compound is adsorbed, i.e., spacious forming primary particles aggregates, where compound 10 might be present. An elementary analysis of the sample by using an EDS probe (energy dispersive X-ray spectroscopy) of SEM indicates the presence of carbon and nitrogen atoms constitutive of the hydrazone structure along with the $\mathrm{Si}$ and $\mathrm{O}$ atoms (Figure 14).

In the next experiment, we performed SEM analyses in two samples obtained as follows: the adsorbed hydrazone $\mathbf{1 0}$ was allowed to react with IBD under the mechanochemical conditions. One sample was obtained after $5 \mathrm{~min}$ of grinding (38\% of conversion to triazole 13 measured by ${ }^{1} \mathrm{H}$ NMR spectroscopy) and allowed to stand at room temperature for $60 \mathrm{~h}$ of aging (total conversion measured by ${ }^{1} \mathrm{H}$ NMR spectroscopy). A second sample was obtained after $15 \mathrm{~min}$ of grinding (total conversion to triazole 13 determined by ${ }^{1} \mathrm{H}$ NMR spectroscopy) and then, as done previously, $60 \mathrm{~h}$ of aging under the same conditions. The SEM images thus contain triazole 13 and are presented in Figure 15.

In both cases, we can see crystalline forms confirmed by XRD experiments (see Supporting Information); nevertheless they are different depending on the experiment. The SEM images in the first case are showing the triazole in the form of a tube where silica is present at both edges of the tube; it seems likely that the aging reaction took place inside the S13 primary particles aggregates; silica is still covering a large part of the triazole. In the second case, triazole is presented in fine needle and silica is much less present in the different extremities.

An elementary analysis of the samples by using an EDS probe (energy dispersive X-ray spectroscopy) of SEM was also performed (Figure 16). Concerning the first experiment, when focusing on the crystal, we can see its composition (carbon, nitrogen, and oxygen atoms) indicating that is the triazole 13 (Figure 16, spectrum 1). We can observe major zones where silica ( $\mathrm{Si}$ and $\mathrm{O}$ atoms) has a strong presence (Figure 16, spectrum 2). The same is also true, respectively, for spectra 3 and 4 (Figure 16).

\section{CONCLUSION}

In the study reported here, we presented the mechanochemical syntheses of 1,2,4-triazoles by using a planetary mill P7 starting from hydralazine hydrochloride $\mathbf{8}$. We found, first, excellent conditions for achieving total conversion to intermediate hydrazones with various aromatic heteroaromatic and phenolic aldehydes in a few minutes in the presence of pyrogenic S13 silica as grinding auxiliary. We analyzed its use in the reaction as essentially being energy transfer to the reactants. The conversion to the annulated 1,2,4-triazoles was optimal with IBD when using nonphenolic hydrazones, while $\mathrm{SeO}_{2}$ was found to be efficient for the latter. We suggest that granulometry and intrinsic constitution of the grinding auxiliary are important in order to optimize the mechanochemical reactions.

SEM images and XRD have shown the morphological forms of grinding auxiliaries before and after grinding and also hydrazone $\mathbf{1 0}$ and triazole 13. For the latter, different crystalline forms were obtained between mechanochemical total conversion of hydrazone $\mathbf{1 0}$ and aging of the reaction. The one-pot two-step synthesis was also successfully conducted in all cases. For the first time, annulated 1,2,4triazoles were obtained in a one-pot two-step procedure by mechanochemical means. Finally, green metrics showed the efficiency of the method in comparison to the conventional syntheses of hydrazone 10 and triazole 13.

\section{AUTHOR INFORMATION}

\section{Corresponding Authors}

Lori Gonnet - Université de Toulouse, IMT Mines Albi, UMR CNRS 5302, Centre RAPSODEE, F-81013 Albi, France; LSPCMIB, CNRS UMR 5068, Paul Sabatier University, 31062 Toulouse, France; 이이이.org/0000-0001-6866-7387; Phone: +33 (0)5 634932 26; Email: lori.gonnet@minesalbi.fr

Michel Baltas - LSPCMIB, CNRS UMR 5068, Paul Sabatier University, 31062 Toulouse, France; 이이이.org/0000-00028785-7095; Phone: +33 (0)5 615562 89; Email: baltas@ chimie.ups-tlse.fr 


\section{Authors}

Christiane André-Barrès - LSPCMIB, CNRS UMR 5068,

Paul Sabatier University, 31062 Toulouse, France;

(1) orcid.org/0000-0002-8973-1875

Brigitte Guidetti - LSPCMIB, CNRS UMR 5068, Paul Sabatier University, 31062 Toulouse, France

Alain Chamayou - Université de Toulouse, IMT Mines Albi, UMR CNRS 5302, Centre RAPSODEE, F-81013 Albi, France

Christophe Menendez - LSPCMIB, CNRS UMR 5068, Paul Sabatier University, 31062 Toulouse, France

Michel Baron - Université de Toulouse, IMT Mines Albi, UMR CNRS 5302, Centre RAPSODEE, F-81013 Albi, France

Rachel Calvet - Université de Toulouse, IMT Mines Albi, UMR CNRS 5302, Centre RAPSODEE, F-81013 Albi, France

Complete contact information is available at:

https://pubs.acs.org/10.1021/acssuschemeng.9b05886

\section{Author Contributions}

The manuscript was written through contributions of all authors. All authors have given approval to the final version of the manuscript.

Notes

The authors declare no competing financial interest.

\section{ACKNOWLEDGMENTS}

The authors would like to gratefully acknowledge the Region Occitanie for thesis grant (L.G.), the CNRS, University Paul Sabatier, and IMT Mines Albi for financial support. The ICT facilities (ICT, Toulouse, France, http://ict.ups-tlse.fr/) and especially those of NMR and Mass spectrometry are gratefully acknowledged for carrying out the corresponding analyses. We also are grateful to the UMS 3623 - Centre de Microcaractérisation Raimond Castaing http://ccarcastaing.cnrs.fr/ for SEM images. We want to thank Sylvie Del Confetto, Philippe Accart, and Veronique Nallet for specific surface areas, particles size, and XRD analyses.

\section{REFERENCES}

(1) Sheldon, R. A. The E Factor: Fifteen Years On. Green Chem. 2007, 9 (12), 1273-1283.

(2) Anastas, P. T.; Warner, J. C. Green Chemistry: Theory and Practice; Oxford University Press: Oxford [England]; New York, 1998.

(3) Tundo, P.; Perosa, A.; Zecchini, F. Methods and Reagents for Green Chemistry - An Introduction; Wiley-Blackwell: Hoboken, N.J, 2007.

(4) Constable, D. J. C.; Curzons, A. D.; Cunningham, V. L. Metrics to 'Green' Chemistry-Which Are the Best? Green Chem. 2002, 4 (6), 521-527.

(5) Jimenez-Gonzalez, C.; Ponder, C. S.; Broxterman, Q. B.; Manley, J. B. Using the Right Green Yardstick: Why Process Mass Intensity Is Used in the Pharmaceutical Industry To Drive More Sustainable Processes. Org. Process Res. Dev. 2011, 15 (4), 912-917.

(6) Metzger, J. O. Solvent-Free Organic Syntheses. Angew. Chem., Int. Ed. 1998, 37 (21), 2975-2978.

(7) Rodríguez, B.; Bruckmann, A.; Rantanen, T.; Bolm, C. SolventFree Carbon-Carbon Bond Formations in Ball Mills. Adv. Synth. Catal. 2007, 349 (14-15), 2213-2233.

(8) Bruckmann, A.; Krebs, A.; Bolm, C. Organocatalytic Reactions: Effects of Ball Milling, Microwave and Ultrasound Irradiation. Green Chem. 2008, 10 (11), 1131-1141.

(9) Tanaka, K.; Toda, F. Solvent-Free Organic Synthesis. Chem. Rev. 2000, 100 (3), 1025-1074.
(10) Waddell, D. C.; Thiel, I.; Clark, T. D.; Marcum, S. T.; Mack, J. Making Kinetic and Thermodynamic Enolates via Solvent-Free High Speed Ball Milling. Green Chem. 2010, 12 (2), 209-211.

(11) Hick, S. M.; Griebel, C.; Restrepo, D. T.; Truitt, J. H.; Buker, E. J.; Bylda, C.; Blair, R. G. Mechanocatalysis for Biomass-Derived Chemicals and Fuels. Green Chem. 2010, 12 (3), 468-474.

(12) Yuan, W.; Friscic, T.; Apperley, D.; James, S. L. High Reactivity of Metal-Organic Frameworks under Grinding Conditions: Parallels with Organic Molecular Materials. Angew. Chem., Int. Ed. 2010, 49 (23), 3916-3919.

(13) Thorwirth, R.; Stolle, A.; Ondruschka, B. Fast Copper-, Ligandand Solvent-Free Sonogashira Coupling in a Ball Mill. Green Chem. 2010, 12 (6), 985-991.

(14) Szuppa, T.; Stolle, A.; Ondruschka, B.; Hopfe, W. Solvent-Free Dehydrogenation of $\gamma$-Terpinene in a Ball Mill: Investigation of Reaction Parameters. Green Chem. 2010, 12 (7), 1288-1294.

(15) Friščić, T.; Mottillo, C.; Titi, H. M. Mechanochemistry for Synthesis. Angew. Chem., Int. Ed. 2020, 58, 2-14.

(16) Tan, D.; García, F. Main Group Mechanochemistry: From Curiosity to Established Protocols. Chem. Soc. Rev. 2019, 48 (8), 2274-2292.

(17) Hayashi, Y. Pot Economy and One-Pot Synthesis. Chem. Sci. 2016, 7 (2), 866-880.

(18) Tyagi, M.; Khurana, D.; Kartha, K. P. R. Solvent-Free Mechanochemical Glycosylation in Ball Mill. Carbohydr. Res. 2013, 379, 55-59.

(19) Konnert, L.; Dimassi, M.; Gonnet, L.; Lamaty, F.; Martinez, J.; Colacino, E. Poly(Ethylene) Glycols and Mechanochemistry for the Preparation of Bioactive 3,5-Disubstituted Hydantoins. RSC Adv. 2016, 6 (43), 36978-36986.

(20) Zhao, Y.; Rocha, S. V.; Swager, T. M. Mechanochemical Synthesis of Extended Iptycenes. J. Am. Chem. Soc. 2016, 138 (42), 13834-13837.

(21) Métro, T.-X.; Bonnamour, J.; Reidon, T.; Sarpoulet, J.; Martinez, J.; Lamaty, F. Mechanosynthesis of Amides in the Total Absence of Organic Solvent from Reaction to Product Recovery. Chem. Commun. 2012, 48 (96), 11781-11783.

(22) Hernández, J. G.; Butler, I. S.; Friščić, T. Multi-Step and MultiComponent Organometallic Synthesis in One Pot Using Orthogonal Mechanochemical Reactions. Chem. Sci. 2014, 5 (9), 3576-3582.

(23) Beillard, A.; Bantreil, X.; Métro, T.-X.; Martinez, J.; Lamaty, F. Mechanochemistry for Facilitated Access to N, N-Diaryl NHC Metal Complexes. New J. Chem. 2017, 41 (3), 1057-1063.

(24) Zhou, C.-H.; Wang, Y. Recent Researches in Triazole Compounds as Medicinal Drugs. Curr. Med. Chem. 2012, 19 (2), 239-280.

(25) Tennefy, A. B. Pesticide Research Trends, 14th ed..; Nova Science Publishers: N. York, 2008.

(26) Reed, C. W.; Yohn, S. E.; Washecheck, J. P.; Roenfanz, H. F.; Quitalig, M. C.; Luscombe, V. B.; Jenkins, M. T.; Rodriguez, A. L.; Engers, D. W.; Blobaum, A. L.; et al. Discovery of an Orally Bioavailable and Central Nervous System (CNS) Penetrant MGlu7 Negative Allosteric Modulator (NAM) in Vivo Tool Compound: N(2-(1H-1,2,4-Triazol-1-Yl)-5-(Trifluoromethoxy)Phenyl)-4-(Cyclopropylmethoxy)-3-Methoxybenzamide (VU6012962). J. Med. Chem. 2019, 62 (3), 1690-1695.

(27) Li, Y.; He, Y.; Shao, T.; Pei, H.; Guo, W.; Mi, D.; Krimm, I.; Zhang, Y.; Wang, P.; Wang, X.; et al. Modification and Biological Evaluation of a Series of 1,5-Diaryl-1,2,4-Triazole Compounds as Novel Agents against Pancreatic Cancer Metastasis through Targeting Myoferlin. J. Med. Chem. 2019, 62 (10), 4949-4966.

(28) De, P.; Koumba Yoya, G.; Constant, P.; Bedos-Belval, F.; Duran, H.; Saffon, N.; Daffé, M.; Baltas, M. Design, Synthesis, and Biological Evaluation of New Cinnamic Derivatives as Antituberculosis Agents. J. Med. Chem. 2011, 54 (5), 1449-1461.

(29) Veau, D.; Krykun, S.; Mori, G.; Orena, B. S.; Pasca, M. R.; Frongia, C.; Lobjois, V.; Chassaing, S.; Lherbet, C.; Baltas, M. Triazolophthalazines: Easily Accessible Compounds with Potent Antitubercular Activity. ChemMedChem 2016, 11 (10), 1078-1089. 
(30) Maddila, S.; Pagadala, R.; Jonnalagadda, S. B. 1,2,4-Triazoles: A Review of Synthetic Approaches and the Biological Activity. Lett. Org. Chem. 2013, 10, 693-714.

(31) Shneine, J.; Alaraji, Y. Chemistry of 1, 2, 4-Triazole: A Review Article. Int. J. Sci. Res. IJSR 2016, 5, 1411.

(32) Carlier, L.; Baron, M.; Chamayou, A.; Couarraze, G. Use of CoGrinding as a Solvent-Free Solid State Method to Synthesize Dibenzophenazines. Tetrahedron Lett. 2011, 52 (36), 4686-4689.

(33) Oliveira, P. F. M.; Baron, M.; Chamayou, A.; Baltas, M.; Guidetti, B.; Haruta, N.; Tanaka, K.; Sato, T. Lowering the Activation Energy under Mechanochemical Conditions: The Case of 2,3Diphenylquinoxaline. ChemistrySelect 2016, 1 (5), 984-988.

(34) Oliveira, P. F. M.; Haruta, N.; Chamayou, A.; Guidetti, B.; Baltas, M.; Tanaka, K.; Sato, T.; Baron, M. Comprehensive Experimental Investigation of Mechanically Induced 1,4-Diazines Synthesis in Solid State. Tetrahedron 2017, 73 (16), 2305-2310.

(35) Oliveira, P. F. M.; Baron, M.; Chamayou, A.; André-Barrès, C.; Guidetti, B.; Baltas, M. Solvent-Free Mechanochemical Route for Green Synthesis of Pharmaceutically Attractive Phenol-Hydrazones. RSC Adv. 2014, 4 (100), 56736-56742.

(36) Oliveira, P. F. M.; Guidetti, B.; Chamayou, A.; André-Barrès, C.; Madacki, J.; Korduláková, J.; Mori, G.; Orena, B. S.; Chiarelli, L. R.; Pasca, M. R.; et al. Mechanochemical Synthesis and Biological Evaluation of Novel Isoniazid Derivatives with Potent Antitubercular Activity. Molecules 2017, 22 (9), 1457.

(37) Ye, Z.; Ding, M.; Wu, Y.; Li, Y.; Hua, W.; Zhang, F. Electrochemical Synthesis of 1,2,4-Triazole-Fused Heterocycles. Green Chem. 2018, 20 (8), 1732-1737.

(38) Szuppa, T.; Stolle, A.; Ondruschka, B.; Hopfe, W. An Alternative Solvent-Free Synthesis of Nopinone under Ball-Milling Conditions: Investigation of Reaction Parameters. ChemSusChem 2010, 3 (10), 1181-1191.

(39) Thorwirth, R.; Bernhardt, F.; Stolle, A.; Ondruschka, B.; Asghari, J. Switchable Selectivity during Oxidation of Anilines in a Ball Mill. Chem. - Eur. J. 2010, 16 (44), 13236-13242.

(40) Schmidt, R.; Stolle, A.; Ondruschka, B. Aromatic Substitution in Ball Mills: Formation of Aryl Chlorides and Bromides Using Potassium Peroxomonosulfate and NaX. Green Chem. 2012, 14 (6), $1673-1679$.

(41) Kaupp, G.; Schmeyers, J.; Boy, J. Iminium Salts in Solid-State Syntheses Giving 100\% Yield. J. Prakt. Chem. 2000, 342 (3), 269280.

(42) Nun, P.; Martin, C.; Martinez, J.; Lamaty, F. Solvent-Free Synthesis of Hydrazones and Their Subsequent N-Alkylation in a BallMill. Tetrahedron 2011, 67 (42), 8187-8194.

(43) Pore, D. M.; Mahadik, S. M.; Desai, U. V. Trichloroisocyanuric Acid-Mediated One-Pot Synthesis of Unsymmetrical 2,5-Disubstituted 1,3,4-Oxadiazoles at Ambient Temperature. Synth. Commun. 2008, 38 (18), 3121-3128.

(44) Sniady, A.; Morreale, M. S.; Wheeler, K. A.; Dembinski, R. Room-Temperature Electrophilic 5-Endo-Dig Chlorocyclization of Alk-3-Yn-1-Ones with the Use of Pool Sanitizer: Synthesis of 3Chlorofurans and 5-Chlorofuropyrimidine Nucleosides. Eur. J. Org. Chem. 2008, 2008 (20), 3449-3452.

(45) Sadana, A. K.; Mirza, Y.; Aneja, K. R.; Prakash, O. Hypervalent Iodine Mediated Synthesis of 1-Aryl/Hetryl-1,2,4-Triazolo[4,3-a] Pyridines and 1-Aryl/Hetryl 5-Methyl-1,2,4-Triazolo[4,3-a]Quinolines as Antibacterial Agents. Eur. J. Med. Chem. 2003, 38 (5), 533-536.

(46) Kumar, R.; Nair, R. R.; Dhiman, S. S.; Sharma, J.; Prakash, O. Organoiodine (III)-Mediated Synthesis of 3-Aryl/Heteroaryl-5,7Dimethyl-1,2,4-Triazolo[4,3-c]Pyrimidines as Antibacterial Agents. Eur. J. Med. Chem. 2009, 44 (5), 2260-2264.

(47) Huang, J.; He, Y.; Wang, Y.; Zhu, Q. Synthesis of Benzimidazoles by PIDA-Promoted Direct $\mathrm{C}(\mathrm{Sp} 2)-\mathrm{H}$ Imidation of N-Arylamidines. Chem. - Eur. J. 2012, 18 (44), 13964-13967.

(48) Cheng, R.; Guo, T.; Zhang-Negrerie, D.; Du, Y.; Zhao, K. OnePot Synthesis of Quinazolinones from Anthranilamides and Aldehydes via $\mathrm{p}$-Toluenesulfonic Acid Catalyzed Cyclocondensation and Phenyliodine Diacetate Mediated Oxidative Dehydrogenation. Synthesis 2013, 45 (21), 2998-3006. 